\title{
Isegoría cosmopolita Cosmopolitan isegory
}

\author{
Helga Lell \\ Conicet / Universidad Nacional de La Pampa \\ hlell@ius.austral.edu.ar
}

Recibido / received:14/03/2016

Aceptado / accepted:13/02/2017

DOI: https://doi.org/10.20318/eunomia.2017.3650

\begin{abstract}
Resumen
En esta voz, se analiza el concepto de "isegoría cosmopolita" como denominación del derecho a participar en la vida política - principalmente, a través del sufragio- de los extranjeros residentes con vocación de permanencia en un territorio estatal. Ello, como forma de asegurar, por un lado, una mayor igualdad en términos democráticos, y, por el otro, como fundamento incondicional y desnacionalizado de los derechos. La propuesta de esta voz conduce a reflexionar en la tensión entre el poder del Estado y la tutela de los individuos.
\end{abstract}

\section{Palabras clave}

Isegoría cosmopolita, ciudadanía, extranjeros, sufragio, derechos, democracia, persona.

\begin{abstract}
In this article, we analyze the concept of "cosmopolitan isegory" as a way to name the right to take active part in political life - mainly, through voting - of foreigners that reside permanently in a State's territory. This, as a way to ensure, on one side, an improvement in terms of democratic equality, and, on the other, as an unconditional and non-national fundament of rights. The proposal here is to think about the tension between the power of the State and individual guarantees.
\end{abstract}

\section{Keywords}

Cosmopolitan isegory, citizenship, foreigners, vote, rights, democracy, person.

SUMARIO. 1. Introducción 2. Algunos conceptos básicos: isonomía e isegoría 3. Etimología 4. Dos modelos de ciudad y de ciudadano 5 . El ciudadano, la persona y los estatutos 6 . El derecho a tener derechos 7. Proyecciones actuales 8 . Consideraciones finales.

\section{Introducción}

Hanna Arendt (2005) destacó que la vida política de Occidente encuentra sus antecedentes fundamentales en dos realidades de la Antigüedad: las polis griegas y la república romana. De estas dos formaciones políticas, derivan muchas de las actuales instituciones - con adaptaciones y cambios mediante, por supuesto- y también en ellas encuentra su génesis gran parte del vocabulario político que nutre y tiñe los estudios teóricos actuales. En este marco, uno de los tópicos más difundidos es el que asocia la noción de democracia y de sus componentes a la antigua Grecia (Gil, 1996: 11). 
Siguiendo estas ideas, aquí se propone explorar el concepto de isegoría, pero, además, se caracteriza un tipo especial de isegoría: la cosmopolita. Este término conceptualiza la capacidad de voto y participación activa de los extranjeros en las actividades democráticas en un territorio en el cual habitan con vocación de permanencia pero de cuya nación no son parte. Usualmente los extranjeros gozan de los mismos derechos y obligaciones que los nacionales, pero no pueden concurrir a la toma de decisiones públicas ni a la creación de las obligaciones que luego recaen sobre ellos.

En síntesis, aquí se propone presentar la voz "isegoría cosmopolita" como denominación del derecho al sufragio de los extranjeros que, a la par que genera una mejoría cualitativa en la simetría democrática (simetría que surge de los parámetros sujetos obligados por las leyes-sujetos que participan de la elaboración de las leyes), también propicia un fundamento desnacionalizado de los derechos.

\section{Algunos conceptos básicos: isonomía e isegoría}

En la antigua Grecia, la democracia era entendida a partir de dos valores: la isonomía, que implicaba la igualdad ante la ley, y la isegoría, esto es, la posibilidad por igual de participar en la esfera pública. La democracia ateniense se ha convertido en un ejemplo paradigmático del poder del pueblo en cuanto a la posibilidad de intervención directa de todos los ciudadanos en la toma de decisiones públicas. Cabe destacar que, en lo material, el ejercicio de esta forma de gobierno poseía muchas limitaciones puesto que los ciudadanos eran muy pocos, solo los varones libres y atenienses eran considerados polites y legitimados para actuar en el marco de las deliberaciones.

Lo que distingue a la democracia en casi todas las versiones que han sido presentadas de ella, en los tiempos antiguos o modernos, es alguna forma de igualdad, o mejor dicho de equilibrio, de superación o absorción de desniveles (Bovero, 1987: 151). ¿Qué igualdad es propia de la democracia? ¿lgualdad entre quiénes? ¿Puede alguien ser excluido de esta igualdad? ¿Igualdad en qué o respecto de qué? En principio, la democracia es definida por la igualdad entre todos los ciudadanos (lo que implica una primera frontera de exclusión), en el derecho/poder de participar en las decisiones colectivas. En términos más rigurosos, la constitución democrática de una organización política se define por la prescripción del tratamiento equitativo de todos los ciudadanos en lo que se refiere a la distribución del derecho/poder mencionado.

Moses Finley (1983: 70-96) señala que para los atenienses la igualdad como isonomía debía darse no sólo frente a la ley sino, sobre todo, a través de la ley, esto es, la democracia requería de la igualdad de derechos políticos de todos los ciudadanos. Aquella igualdad no sólo significaba el derecho de votar, de ejercer los cargos públicos sino ante todo el derecho de participar en la elaboración de las directrices políticas en el Consejo y en la Asamblea. También destaca que, a principios del siglo $\mathrm{V}$, surgió otro término deslindado del de isonomía: el de isegoría. Este nuevo término significa libertad de palabra en el sentido de derecho de hablar en voz alta en la Asamblea de todos los ciudadanos. Debe agregarse que el significado democrático de isegoría no radica en el ser una libertad sino en ser una igualdad (Bovero, 1987: 153). Para Resnik (1996: 173-175), isonomía e isegoría están íntimamente ligados puesto que la primera, implícitamente, engendra también la necesidad de cierto grado efectivo de participación ciudadana, y la segunda es la que consagra esta dimensión participativa.

A este panorama, cabe agregar un interesante argumento respecto de la 
constitución democrática ateniense que presenta Gil y que presenta, de alguna manera, la relación entre la nacionalidad y la posibilidad de participar en la esfera pública ( $\mathrm{y}$, por lo tanto, la repulsión de la participación de los no nacionales). Dice este autor que es necesario prestar atención al discurso de Aspasia en el Menéxeno platónico (cf. 238d-239a) puesto que es un testimonio claro acerca de cómo opera el mito de la autoctonía como justificación del régimen de gobierno del pueblo. Ser ateniense de nacimiento era un valor supremo. En aquel diálogo, dice este autor, "la democracia al nivel de la ideología popular, recibe una justificación de la más pura raigambre racista y despectiva hacia el resto de los griegos, pero que les hacía estar a los atenienses tan orgullosos de sí mismos como su sistema de gobierno" (Gil, 1996: 21). Conforme con ello, para ser $\varepsilon \lambda \varepsilon u ́ \theta \varepsilon \rho o$, es decir, libres, que ningún ciudadano sea amo de otro, y para fundamentar la íovopía o igualdad en derechos y obligaciones, es necesaria la igualdad de linaje, esto es, la íooyovía.

\section{Los elementos del concepto "isegoría cosmopolita"}

La palabra "isegoría" da nombre al derecho/poder de todos los ciudadanos de pronunciar su parecer en las deliberaciones públicas, además de participar activamente en otras instituciones de la vida en común. Los componentes léxicos serían el prefijo íoos (isos), que significa "igual", äyopa (ágora), esto es, "plaza pública" o, en cierta manera, "asamblea", más el sufijo "-ı" (-ía) que denota cualidad. ${ }^{1}$

En cuanto al vocablo "cosmopolita", este proviene del griego "кобното入íтns",

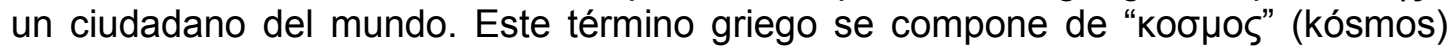
que significa "mundo, universo, orden" у "то入і́тns" (polítes), es decir, el ciudadano o miembro de la polis.

En cuanto a este último término cabe agregar que surge de un diálogo en el que Diógenes de Sínope lo utiliza cuando responde a la pregunta por su ciudad natal, ser "ciudadano del mundo". No obstante, una referencia similar aparece en un texto en latín de la autoría de Marco Tulio Cicerón quien destacó que el mundo en su totalidad ha de ser considerado una única comunidad de ciudadanos ${ }^{2}$.

Finalmente, resulta interesante analizar la noción de extranjero. Señala Benveniste que esta no se define, en las civilizaciones antiguas, por criterios constantes como en las sociedades modernas. El término "گ́́vos" (xénos), extranjero y hospedado, denota alguien nacido en otra parte que, unido por ciertas convenciones, goza de derechos específicos; es decir, es el extranjero que se beneficia de las leyes de hospitalidad. En latín, el extranjero que viene de fuera es el aduena y aquel que está fuera de los límites de la comunidad es el peregrinus. Para Benveniste esto da cuenta de que la definición de extranjero en la Antigüedad no es estática sino que, en la diversidad de estas nociones, el extranjero es siempre un extranjero particular, aquel que depende de un estatuto distinto.

Lo anterior solo puede comprenderse a partir de la idea de que el extranjero es un enemigo con el cual, transitoriamente, se pueden establecer términos de paz. Ello, en tanto el que ha nacido fuera es a priori un enemigo, lo cual a su vez motiva un compromiso mutuo para establecer entre él y yo/nosotros relaciones de hospitalidad que no serían concebibles en el seno mismo de la comunidad.

\footnotetext{
1 Para determinar la etimología y los significados de esta palabra y de las que continúan se ha recurrido a la siguiente bibliografía: Corominas, 2005, Chantraine, 1968, Ernout y Meillet, 2001, Lidell y Scott, 1996

2 "Universus hic mundus una civitas existimanda". Cicero. De legibus I 7, 22.
} 


\section{Dos modelos de ciudad y de ciudadanos}

Indagar en la ciudadanía como concepto constituido por la isegoría requiere necesariamente comprender qué es la ciudad y cuál es su relación con los ciudadanos. El ejercicio del derecho de pronunciarse y de participar activamente en los asuntos públicos de la comunidad en la que se está inmerso parte de la base y las limitaciones que la relación con la ciudad establece. ¿Cómo se define al ciudadano? ¿La ciudad constituye al ciudadano o viceversa?

Etimológicamente, la formación de civitas proviene del abstracto en -tās derivado de civis. El problema aquí radica en que la traducción de civis por ciudadano resulta errónea por cuanto implicaría que el ciudadano romano se define por su vínculo con una ciudad (al igual que la relación polis-polites). Sin embargo, en este caso el latín civis es el término primario y civitas el derivado. La ciudad se define por los ciudadanos y no al revés. Como formación de abstracto, civitas designará propiamente el conjunto de los cives (Benveniste, 1983 y 1999).

Un modelo distinto de esta misma relación es dado por el griego. Los

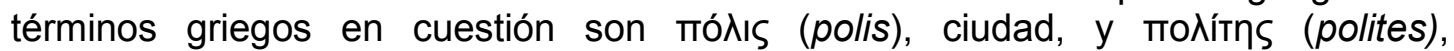
ciudadano. Esta vez, el derivado en -ITnS (-itēs) se determina en relación con el término básico de polis y designa a quien participa en la vida pública de la ciudad, el que tiene voz en los debates y los derechos y obligaciones conforme su condición.

Lo anterior resulta de interés para repensar la isegoría cosmopolita en clave actual ya que muestra que, según se ponga el acento en el Estado como definidor de derechos de participación política o en el individuo como elemento constituyente del Estado y, por lo tanto, como sujeto con derechos preexistentes a este, se tiene una visión acerca de quiénes son considerados parte del Estado y protegidos por este. Si se piensa, por ejemplo, en el caso de los refugiados, ¿por qué deberían ser recibidos por un Estado diferente al de su origen? ¿Qué derechos deben gozar en el nuevo territorio? ¿Puede el Estado receptor generar fuertes políticas discriminatorias? Si se opta por el primer extremo, es decir, por un ciudadano que se define a partir de su pertenencia a la ciudad, entonces, es el Estado el que decide quién es parte y quién no. Por lo tanto, no existen planteos posibles ante "la parte de los sin parte" (Rancière, 2009). En cambio, si se elige la segunda opción, es decir, concebir al sujeto como un portador de derechos por su sola humanidad y como base formadora de la ciudad, entonces, no existen argumentos sólidos para sostener una exclusión de la esfera política de quienes residen en el territorio.

\section{El ciudadano, la persona y los estatutos}

En su obra titulada Les Grecs ont-ils cru à leurs mythes?, Veyne (1992) señaló que, si bien desde el siglo VI a.C. los griegos ya no habrían interpretado de manera literal sus mitos, estos últimos continuaban en vigencia por su valor pedagógico. El concepto de persona no surge de un mito; no obstante, con él ocurre algo semejante al fenómeno de aquellas creencias helénicas puesto que son formas constitutivas de cierto imaginario social.

En principio, la génesis del término "persona" lo vincula a un elemento utilizado por el ser humano y no al ser humano mismo. La etimología de esta palabra remite a la persōna, la máscara teatral romana mediante la cual se representaban diferentes personajes en el escenario y que permitía la ampliación de las voces para que fueran audibles para el público. A su vez, este término se

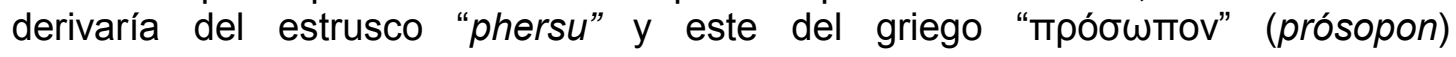


(Corominas, 2005, Ferrater Mora, 2004 y Di Pietro y Lapieza Elli, 1982). Como puede notarse fácilmente, la idea literal remite al rol ejercido en cierto contexto o bien a la tecnología corporal que permite al ser humano presentarse en escena y tener voz como cierto personaje. No es relevante quién es el actor, quién es el sujeto o el ser humano detrás de la máscara, lo que importa es qué papel le permite jugar dicho elemento, papel que se representa solo a partir del uso de la máscara. Claro está que no es el objeto el que adquiere y concreta derechos, entre ellos, el de participar en la esfera pública, pero sí representa algo: la disociación con el hombre y la aparición de los estatus o roles a ejercer (o que se está impedido de ejercer).

Sabes que eres el actor de un espectáculo, elegido por el director del teatro, breve si lo desea breve, largo, si lo desea largo; y si él quiere que hagas de mendigo, tienes que hacer bien esta parte; y lo mismo si se trata de un tullido, un príncipe o un ciudadano particular. Tu tarea consiste en hacer bien la parte que te ha sido asignada; elegirla, sin embargo, corresponde a otro (Epicteto, Enchiridion, 17).

Esta cita arroja algunos conceptos claves sobre los que se intenta reflexionar en estas páginas: en primer lugar y principalmente, la persona como concepto y metáfora del discurso jurídico que parte de la máscara que da voz al actor y su rol en una obra, en este caso, su posibilidad de ser participante activo en la toma de decisiones públicas en el marco de procedimientos democráticos; en segundo término, la asignación de roles por parte de un sujeto facultado para ello. ¿A quién le corresponde el derecho de utilizar la voz de la isegoría de los ciudadanos: a los ciudadanos mismos o es una dádiva que concede el Estado? ¿Se es ciudadano por participar en la esfera pública o se participa por ser ciudadano?

En el derecho romano, las personas son distinguidas con base en su status, es decir, en relación con los tres valores fundamentales de la libertas, de la civitas y de la familia. A cada estatus le corresponde un rol diferente. Por lo tanto, si se quiere observar la estructura jurídica de la persona, se deben tener en cuenta las situaciones existenciales que son indicadores de posesión de determinados derechos y deberes, de formas particulares de tutela jurídica y prerrogativas específicas (Viola, 2015: 6). Entre estos roles a jugar se encuentra el de ciudadano o de no ciudadano.

El habitante de la ciudad es también un actor; pero un actor es (...) alguien que sabe o que ha llegado a saber desempeñarse en varios escenarios, que debe por lo tanto saber integrar las situaciones y definir cada una de ellas en su propiedad. Ese es el saber vivir del hombre de la ciudad y no ya solamente el saber del hombre mundano en el sentido estrecho del término: definir y redefinir una situación (Joseph, 1988: 30).

Así, el extranjero en un Estado engloba múltiples roles a jugar: es el nacional de otro país, es el no ciudadano del lugar en el cual se encuentra, es el que está donde no pertenece y pertenece donde no está, no es su elección dónde pertenecer aunque pueda elegir dónde estar.

Para realizar un salto temporal y dejar de lado la Edad Media y la Modernidad que presentan concepciones propias de la persona, es necesario volcar la mirada en la actualidad. La época contemporánea, señala Viola, se caracteriza por el retorno del individuo y por el auge de los derechos humanos.

En este marco, el sistema internacional de protección de derechos humanos contemporáneo pretende asegurar los aspectos fundamentales de la persona desde el punto de vista individual, social y político. Esta tarea resulta de gran complejidad puesto que requiere pesar derechos de la más variada gama conforme a los roles 
de los sujetos: derecho de libertad, derechos civiles, derechos sociales, derechos de incidencia colectiva, derechos culturales, derechos económicos, derechos políticos, derechos medioambientales, etc. Esto le permite a Viola señalar que se debe ser consciente del acaecimiento del retorno de los status. A diferencia de la Antigüedad, ahora el individuo es considerado no ya como igual en abstracto sino a partir del reconocimiento de su diversidad, de su colocación en contextos de vida particular y en situaciones específicas.

Ciertamente existe una diferencia con respecto a los status del derecho romano y no sólo porque nuevos status se han sumado y los viejos han asumido significados nuevos. Los status de hoy son aquellos del sexo (hombre, mujer, homosexual...), de la edad (infancia, ancianidad), de la salud, de la ciudadanía, del trabajo, del consumidor de productos, del usuario de servicios, del embrión... Es casi superfluo notar que formas de vida diversas van asumiendo el rol de status en la medida en que son conectados a la tutela jurídica de situaciones particulares en los cuales los individuos se encuentran por razones existenciales (Viola, 2015: 15).

Lo anterior significa el paso desde la política de la igual atribución de derechos y obligaciones en abstracto a la política de la diversidad dialógica para que, en el marco de la democracia, sea una pregunta central qué cosas comunes existen entre individuos tan diferentes entre ellos en la cultura y en los proyectos de vida (Viola, 2015: 11-16).

Ahora bien, ¿puede existir una armonía democrática y dialógica sin la respectiva isegoría? La aceptación de los desplazamientos territoriales, en este marco, debería permitir repensar nuevas formas de plantear los derechos humanos que no dependan de las construcciones estatales-nacionales y territoriales.

\section{El derecho a tener derechos}

Hanna Arendt plantea, en Los orígenes del totalitarismo y, en menor medida, en Eichmann en Jerusalén, la situación de desprotección en la que se encuentran ciertas minorías frente a los gobiernos de los Estados Nación. Principalmente, tiene como referencia el caso de los apátridas que, perseguidos por los totalitarismos, no se encuentran protegidos por ninguna entidad. Los derechos humanos, tal como aparecen en la Declaración Universal de 1948 son abstractos, parten de un modelo de hombre no situado en ningún espacio en concreto. Si bien son concebidos como inalienables, acaban por ser responsabilidad de un Estado que los reclame frente a otro par violador. No es la naturaleza humana en abstracto la que efectivizará dicho derecho sino que esta tarea queda a cargo del sistema estatal.

Los derechos del hombre, después de todo, habían sido definidos como "inalienables" porque se suponía que eran independientes de todos los gobiernos; pero resultó que, en el momento en que los seres humanos carecían de su propio gobierno y tenían que recurrir a sus mínimos derechos, no quedaba ninguna autoridad para protegerles ni ninguna institución que deseara garantizarlos (Arendt, 2013: 414)

Aquellas minorías que no cuentan con un gobierno en ningún Estado son fáciles blancos de avasallamiento. En particular, esta posición se relaciona con la imposibilidad de participar en la elaboración del marco legal-estatal que los aparta de la esfera de tutela y que podría ser la herramienta de garantía.

Así, el derecho a tener derechos se erige en la reflexión acerca de la necesidad de otorgar la posibilidad de participar en la elaboración del derecho, de las normas jurídicas, que crean tutelas, cargas y obligaciones. De esta manera, el 
fundamento último de los derechos humanos y la responsabilidad de concreción de ellos exceden al mero Estado como autoridad. Así, se revierte la preminencia del colectivo por sobre el individuo para que este último sea titular del derecho a ser parte de un colectivo organizado que vele por él.

En línea con este planteo, Susana Villavicencio (2007) reflexiona sobre la condición paradójica de la democracia liberal que se ha expandido en los países de Occidente puesto que mientras se afianza en sus condiciones formales, materialmente, durante la década de los noventa, ha sido transformada por su sujeción a los dictados del mercado y la economía transnacional capitalista. Particularmente, resulta preocupante la situación en Latinoamérica debido a que el debilitamiento del sistema institucional es acompañado por la exclusión de gran parte de sus pobladores del sistema de reparto social y político y por una profunda ampliación de la brecha entre pobres y ricos. En ese contexto, la autora se pregunta qué significa ser ciudadanos.

La ciudadanía es definida como un estatus que garantiza a los individuos iguales derechos, deberes, libertades, restricciones, poderes y responsabilidades. "Pero son precisamente las situaciones de exclusión, las desigualdades crecientes y la falta de condiciones para el ejercicio de los derechos las que no cesan de mostrar su insuficiencia o de revelar un vacío a llenar" (Villavicencio, 2007: 39). Esto conduce a cuestionar la brecha existente entre el derecho ideal, el que debe ser, y el que efectivamente es.

El primer derecho es el de la pertenencia a una comunidad política. Así, cuando se trata de reconocer la ciudadanía, se trata de asignar condiciones de posibilidad de la supervivencia como seres humanos. Entonces, si teóricamente los derechos humanos se constituyeron como un límite frente a los avances del Estado por sobre el derecho, la experiencia de los totalitarismos coloca a la ciudadanía como base del reconocimiento de estos. De esta situación deriva la autora la expresión arendtiana de "el derecho a tener derechos" ya que un grupo cuya ciudadanía es negada se encuentra en una posición de total desprotección y condenado a la pérdida de su subjetividad política (Villavicencio, 2007). La negación de derechos es, entonces, en el marco de atribución jurídica de potencias e impotencias, la parte de los sin parte (Rancière, 2009).

A partir de estos presupuestos, la propuesta de Villavicencio no es la apelación a los derechos humanos como horizonte de resolución de conflictos, sino una transformación activa que transforme las situaciones de exclusión en inclusión.

...la idea del "derecho a tener derechos" pone en cuestión la lógica formalista de los derechos y lleva, más bien, a mirar que los reclamos de los "sin derechos" son expresión directa de la dinámica de creación de derechos. En este sentido, la experiencia latinoamericana es distintiva en formas de lucha frente a la exclusión, emprendida por las comunidades indígenas, los desempleados, las comunidades que han visto cerrarse sus mundos de vida a causa de las crisis económicas. (Villavicencio, 2007: 45).

En cuanto a la política de los derechos humanos, sin restar importancia al discurso sobre ellos, resulta necesario el análisis de las tensiones que genera su invocación en el marco de las democracias liberales contemporáneas ya que, con base en un presupuesto individualista y a-histórico, se difunde un discurso jurídico que convive con el incremento de las zonas fuera del derecho y con las figuras de los "sin derecho". Son precisamente estas figuras las que dan cuenta de la inevitable relación entre el derecho y otros órdenes de la vida humana como la economía, la 
moral, la política, etc. (Villavicencio, 2007).

La autora concluye que el concepto de ciudadanía como estatus de derechos puede ser dejado de lado y ser reemplazado por uno que la considere como un carácter incondicional de lo político definido por el derecho a tener derechos.

\section{Proyecciones actuales}

La isegoría cosmopolita como tópico a discutir se presenta en el marco de un conjunto de fenómenos actuales que acaecen en un mundo globalizado y en el cual los desplazamientos territoriales y el aumento de la xenofobia se hacen cada vez más frecuentes. En este contexto, se encuentra en el eje de los debates actuales en torno a la expansión o no del ejercicio de la ciudadanía activa y del sufragio. Un ejemplo lo constituye el caso de Argentina, donde, a nivel nacional, en los últimos cinco años, se han presentado dos proyectos en el Congreso tendientes a lograr el voto extranjero (uno, en 2012, que fue archivado, y otro, en 2016, a tratarse en el futuro). Asimismo, en dicho país los extranjeros tienen participación (con diferentes regulaciones) en casi todas las jurisdicciones provinciales (la excepción es la provincia de Formosa en la cual está prohibido constitucionalmente).

En otro orden de ideas, la trascendencia de los sucesos a nivel internacional respecto de los procesos migratorios y la absorción de los extranjeros y sus descendientes (que muchas veces son nacionales de los Estados a los cuales sus ascendientes inmigraron/emigraron) ponen en primer plano la necesidad de redoblar los esfuerzos de reflexión tanto teóricos como prácticos. Basten, a mero título de mención, los recientes y afamados atentados en Francia, Alemania, Turquía y Bélgica (entre otros que han cobrado menor calibre mediático), el flujo migratorio desde Siria a los países de la Unión Europea, el cierre de fronteras de países europeos, el crecimiento de movimientos políticos que propugnan en sus campañas medidas explícitamente xenófobas o las constantes noticias de migrantes que son rescatados en las cercanías de las costas europeas procurando ingresar a distintos países a pesar del riesgo vital que corren, o casos de muerte en el proceso de migración, como fue el caso del niño Aylan Kurdi aparecido ahogado en la playa turca, o en los sucesos que acaecen corrientemente en la frontera entre México y Estados Unidos o entre Cuba y Estados Unidos, o incluso la revisión actual de la política migratoria estadounidense o la concentración de la atención de los organismos internacionales en los graves problemas de la niñez migrante, entre tantos otros ejemplos que resultan innumerables.

Como señala Faralli (2013), uno de los tres grandes desafíos de la Filosofía del Derecho en el siglo XXI gira en torno a cómo concebir los derechos humanos de los migrantes dado que la globalización, las modificaciones en el ejercicio de las soberanías estatales, los procesos de integración, la realidad económica en el marco de procesos de acentuación de las relaciones de mercado, los regímenes de acumulación caracterizados por la desigualdad y de exilios a causa del neoliberalismo desafían a los tradicionales conceptos modernos de ciudadanía y nacionalidad.

\section{Consideraciones finales}

La isegoría ha constituido, junto con la isonomía, uno de los pilares básicos de la antigua democracia al consagrar la igualdad de derecho de pronunciarse en la esfera pública, es decir, en aquella en donde las normas jurídicas eran elaboradas. 
Era la igualdad de participar activamente en las deliberaciones del ágora. La isonomía, por su parte, era la igualdad ante la ley, es decir, el derecho de ser tratado de la misma manera que los pares ciudadanos. Estas nociones, íntimamente relacionadas, se diferencian por cuanto la primera funciona a priori de la creación de la norma jurídica, es decir, antes de que esta sea impuesta; en cambio, la segunda, es a posteriori, o sea, una vez que esta prescripción ha sido creada.

El calificativo de "cosmopolita" proviene de la idea de un orden sin fronteras, es decir, de la ciudadanía del universo, del cosmos (en el sentido en el que los antiguos griegos lo comprendieron). En la actualidad argentina, la isonomía cosmopolita se encuentra garantizada desde el plano constitucional, no así la isegoría cosmopolita.

Indagar en la ciudadanía, ya sea del universo, de una ciudad o de una polis, implica pensar en la relación entre la isegoría y dicha ciudadanía. ¿Es esta última condición de la primera? Se ha señalado anteriormente que la condición de ser nacido en Atenas parecía ser un requisito esencial para la participación política, al menos según lo transcrito del Menéxeno platónico. No obstante, parece posible establecer excepciones a este principio.

La clave para comprender esta última oración puede ser hallada en el concepto de extranjero mismo, en el xénos. Este era un enemigo solo por el hecho de haber nacido en otro territorio, pero también era un posible amigo, alguien con quien podía establecerse una paz transitoria y a quien se le podían dispendiar ciertos tratos especiales en razón de hospitalidad. Como señaló Benveniste, los parámetros para establecer las múltiples relaciones con los extranjeros son dinámicas. Así, un extranjero puede ser receptor de un trato de polítes, aunque nunca será tal. Para el ámbito romano, vale señalar una mayor claridad en las relaciones: un ciudadano solo es tal para otro ciudadano (la ciudad solo se define en relación a un conjunto de cives). Un hostis es tal para otro hostis. Es el vínculo mutuo lo que define sus estatus.

Con relación a lo dicho en última instancia, cabe destacar el juego de primacías que encierran los binomios polis-polites y civitas-cives. Mientras que en el par griego, el estatuto del polítes se definía por su pertenencia al colectivo previo, en el romano era a la inversa. Esto resulta de interés de cara a pensar en un fundamento de los derechos más allá de la relación con un Estado nación arraigado en un territorio.

Por último, cabe resaltar que la ciudad como campo de lo común se erige en un escenario en cuyo espacio se ejercitan roles construidos socialmente. La ciudad marca los movimientos posibles y los no permitidos, los sujetos que sobre él se desenvuelven deben reconocer cuál es su parte en el reparto de potencias e impotencias. En tal sentido, es posible recuperar una de las nociones fundamentales de la teoría general del derecho como es la de persona. Esta nace de una metáfora que se remonta a las antiguas máscaras de Grecia y Roma y actualmente, en el campo jurídico, se la entiende como un núcleo de imputación de derechos y obligaciones. Se es persona en relación con un rol, con un estatuto: contratantes, proveedor/usuario, progenitor/hijo, consumidor, administración/administrado, etc. No obstante el hecho de que es esta metáfora la que permanentemente se trae a colación en tiempos contemporáneos, cabe recuperar otro sentido que permanente entra en pugna con aquel y que también ha anclado fuertemente en el espacio de los derechos humanos: el moderno, el de persona como sujeto de derechos. De esta manera, aparece la pregunta acerca de si es posible combinar algunos roles/estatus de la persona (como, por ejemplo, el de extranjero) sin resignar la 
subjetividad humana como sostén de los derechos.

Así, a partir de estos planteos es que se llega a la isegoría cosmopolita identificada como el derecho a tener derechos, esto es, como una condición democrática de los Estados en los cuales los eventuales destinatarios de las normas jurídicas sean partícipes de su elaboración. Si se acepta la posibilidad de una participación incondicionada respecto de una nación territorialmente vinculada de la toma de la palabra en la esfera común, entonces, se reconoce el derecho/libertad a cada individuo de luchar por su propia tutela.

Ahora bien, si la democracia se construye sobre el concepto de isegoría, ¿es esta exclusión democrática? ¿Es posible pensar en una isegoría cosmopolita en los Estados actuales?

\section{Bibliografía}

ARENDT, H. (2005), ¿Qué es la política? Rosa Sala Carbó (trad.), Paidós, Barcelona.

ARENDT, H. (1948/2013), Los orígenes del totalitarismo, Alianza, Madrid.

BENEITEZ, B. (2005), "La ciudadanía en la democracia ateniense", Foro Interno. Anuario de Teoría Política. $N^{\circ}$ 5, pp. 37-58.

BENVENISTE, É. (1983), Vocabulario de las instituciones indoeuropeas, Taurus, Madrid.

BENVENISTE, É. (1999), "Dos modelos lingüísticos de la ciudad". En: Problemas de lingüística general II, México, Siglo XXI Editores, pp. 274-282.

BOVERO, M. (1987), "Sobre los fundamentos filosóficos de la democracia", Dianoia, Vol. 33, N³3, pp. 149-165.

CHANTRAINE, P. (1968), Dictionnaire Étymologique de la Langue Greque. Histoire des mots. Tomos I y III, Éditions Klincksieck, Paris.

COROMINAS, J. (2005), Breve diccionario etimológico de la lengua castellana, Gredos, Madrid.

DI PIETRO, A. y LAPIEZA ELLI, E. (1982), Manual de Derecho Romano, Depalma, Buenos Aires.

ERNOUT, A. y MEILLET, A. (2001), Dictionnaire étimologique de la langue latine. Histoire des mots, Éditions Klincksieck, París.

FARALLI, C. (2013), La filosofia del diritto contemporanea. I temi e le sfide. Laterza, Bari.

FERRARI, J. L. y MIRANDA, L. R. (2012). Europa, Europae: textos y contextos para reflexionar sobre los temas de la tradición occidental, Biebel, Buenos Aires.

FERRATER MORA, J. (2004), "Persona". En: Diccionario de Filosofía. Tomo III (KP). Barcelona, Ariel.

FINLEY, M. (1983). Politics in the Ancient world. Cambridge University Press, Cambridge.

GIL, L. (1996). "Sobre la raigambre griega del sistema democrático", Cuadernos de Filología Clásica. Estudios griegos e indoeuropeos, Vol. 6, pp. 11-21.

JOSEPH, I. (1988), El transeúnte y el espacio urbano. Sobre la dispersión y el espacio público, Gedisa, Barcelona.

LIDELL, H. G. y SCOTT, R. (1996), A Greek-English Lexicon. Clarendon Press, Oxford.

RANCIĖRE, J. (2009). El reparto de lo sensible: estética y política, Libros ArcesLOM Ediciones, Santiago de Chile.

RESNICK, P. (1996), "Isonomía, Isegoría, Isomoiría y democracia a escala global", Isegoría, $\mathrm{N}^{\circ} 13$, pp. 170-184.

VEYNE, P. (1992), Les Grecs ont-ils cru à leurs mythes?, Editions du Suil, Paris.

VILLAVICENCIO, S. (2007), "Ciudadanía y civilidad. Acerca del derecho a tener 
derechos", Colombia internacional, Julio-Diciembre, N 066, pp. 36-51.

VIOLA, F. (2015), "El estatuto jurídico de la persona", Derecho y cambio social, $\mathrm{N}^{\circ}$ 40, Año XII, pp. 1-20. 